\title{
Causes of Filtration the Water in Roller Compacted Concrete Dams (RCC)
}

\author{
[J. O. Morandi, R. J. Uliarte, A. E. Carmona.]
}

Abstract- Roller compacted concrete (RCC) dam construction involves placing by compaction vibratory of concrete in successive layers of 30 to $45 \mathrm{~cm}$ thick. The RCC is a permeable material, especially on the surfaces of contact between layers, which are flat or together of potential weakness for the material.

This constructive technology generates two areas of transition with RCC body dams it. A with the face of mass vivrate concrete (MVC) and the other with the rock of the footboard.

The impermeability of the dam must rely to a thin layer of MVC, of the order of $0,70 \mathrm{~m}$ to $1,30 \mathrm{~m}$ thick, which forms a waterproof wall in contact with the water of the reservoir. It is complemented by joint water stop placed in the joints between blocks.

A crack in the wall or placement joints defects water stop will allow the entrance of water to the body of the dam. If the constructive joints and transition areas were not resolved correctly, they will operate as preferential pathways of spatially connected at all the dam water circulation, so that you emerge in the face of water down a place away from the entry point. Therefore it is difficult to diagnosis and consequently the project.

The water through the body of the dam can cause progressive deterioration of concrete due to leaching of calcium hydroxide by what while filtration volumes were eligible, at the time probably undertake the security of the dam.

This paper presents a case and the reasons which gave rise to the waterproofing failures, processes observed deterioration and constructive recommendations to prevent the occurrence of such failures.

Keywords - Concrete Roller Compacted (RCC) * Dams *.

J. O. Morandi

Institute of Materials and Soils

Faculty of Engineering, National University of San Juan San Juan, Argentina

\section{R. J. Uliarte}

Institute of Materials and Soils

Faculty of Engineering, National University of San Juan San Juan, Argentina

\section{A. E. Carmona}

Institute of Materials and Soils

Faculty of Engineering, National University of San Juan

San Juan, Argentina

\section{Introduction}

This paper presents the review of the causes of water filtration in a dam of Roller Compacted Concrete (RCC) and the associated processes of deterioration that may compromise the security of the Dam in the future.

The Figure 1 and 2 shows the exterior and interior state of the dam.

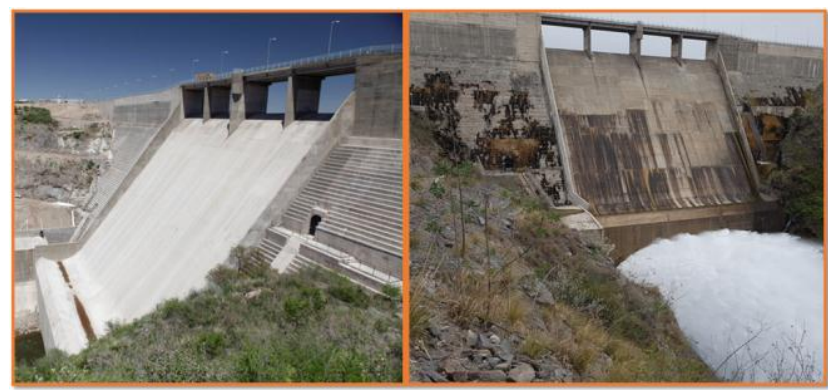

Figure 1. Photos. The dam presents the day of the inauguration, and five years later. There is upwelling of water on the wall waters down by leaks

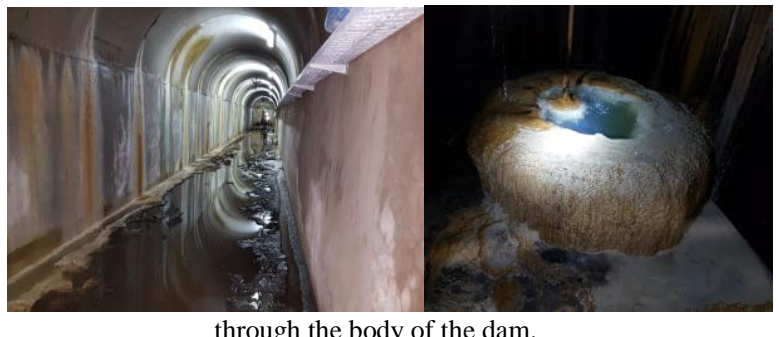

Figure 2. Photos. The interior of the dam is shown. Left a gallery of inspection and the inverted pendulus of auscultation system right. There is large amount of deposits of hydroxide of calcium leached from the body of the dam.

\section{A. Roller Compacted Concrete (RCC).}

The RCC is a material consisting of aggregates, cement, water (to a lesser extent than for a conventional concrete) and additives (optional). Their increased use has been in the construction of dams. It is a material of almost zero settlement, placed in successive layers on a continuous basis, its consolidation is performed with a vibratory roller, do not use steel reinforcement and formwork for placement.

In the RCC, coarse and fine aggregates constitute approximately 75 to $85 \%$ of the volume of the mixture. The cement to be used can be Portland cement (type I or type II), whose content in the mixture is between 10 to $17 \%$ by dry weight of aggregates, in the order of 80 to $140 \mathrm{Kg} / \mathrm{m}^{3}$.

The use of the HCR as a fast, economical, technically suitable and safe alternative for construction of mass concrete, presents advantages compared to conventional concrete and dams of loose materials. Economy at the time of construction, commissioning work, cement and volume of 
Proc. of Eighth International Conference On Advances in Civil, Structural and Mechanical Engineering - ACSM 2018 Copyright (C) Institute of Research Engineers and Doctors, USA. All rights reserved. ISBN: 978-1-63248-154-2 doi: 10.15224/978-1-63248-154-2-27

materials. Ease of movement of workers, machinery and materials, streamlining the construction process and structural reliability.

Construction process of the RCC. Can be used both for transport, placement and compaction of the concrete methods commonly used for the movement of soils, which, coupled with powerful manufacturing methods, such as those of continuous production of concrete, derived in the obtaining very high yields of construction.

Horizontal joints. The thickness of each layer is limited by the depth to which the vibratory roller is effective, without segregations in the mix. The separation between layer is what constitutes the horizontal joint of construction. The surface of each new layer must remain clean, damp during exposure outdoors. The hardened surface must undergo treatment before being covered with the next layer. It is essential to provide good adhesion between consecutive layers in all the horizontally joint, so that the whole work as a monolithic structure. Cement content is low in the employed concrete as to give the required locking, it is very useful to extend on the surface a thin layer of mortar or paste rich concrete cement (grout). The layer thickness should not exceed $30 \mathrm{~cm}$. The compaction roller, depending on the workability of the mix, must be ensure a complete consolidation.

\section{Considerations of Design and Construction}

\section{A. Impermeability of RCC Dams.}

RCC dam design considers the watertightness is given by a wall of upstream (Parament), executed with Concrete Conventional Vibrated (CCV) of thin thickness, which is normally on the order of $1,00 \mathrm{~m}$.

To make waterproof the mentioned facing of $\mathrm{HCV}$ is must fulfil the following conditions:

- The Parament should not be fissure.

- Joints water-stop placed between blocks must be properly anchored in both blocks.

It should any of them fail the water from the reservoir will be in contact with the body of the dam RCC enabling the flow of water through it.

\section{B. Constructive Considerations}

Compaction defect in contacts. If the layer of RCC is placed first and then that of $\mathrm{CCV}$, cannot compacted and integrate both concrete. The order is reverse, first $\mathrm{CCV}$ should be and then the RCC to to integrate them. This error may cause a defect of compaction in the contact between $\mathrm{CCV}$ and RCC. It can be in the facing upstream, in the face of the waters below, in brackets, in construction joints (cold joints) by disruption of the placement of the concrete and in contact with pipes, ducts, and galleries.

This in turn leads to areas of high porosity and high permeability, which can operate as drains. These drainage areas facilitate the draining of water through the dam and mask its travel.

Figure 3 shows an example of this construction defect.
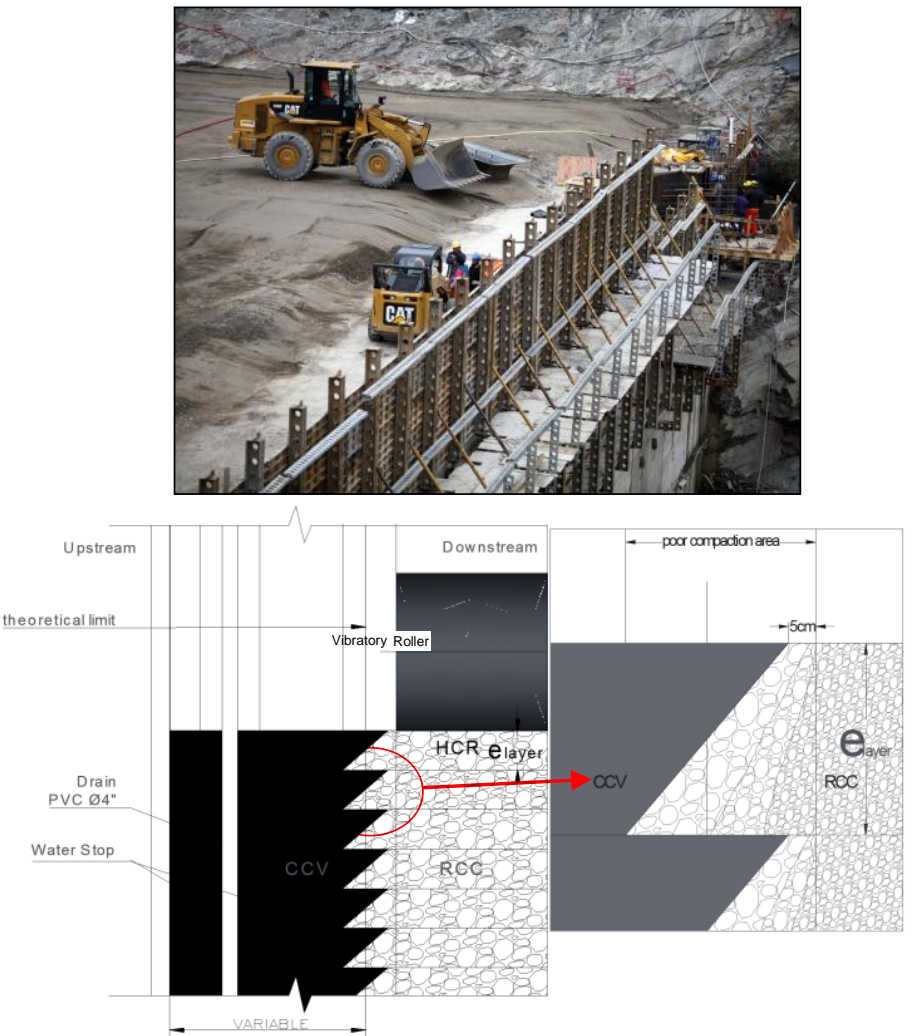

Figure 3. The photo above shows an example in which being placed incorrectly, first RCC layer and then the facing CCV. The figure below shows an outline of the areas of defective compaction.

Defect of anchorage of the Joint Water-Stop. It is produced by a failure on the anchor of the Board with the HCV which also it is not compacted properly

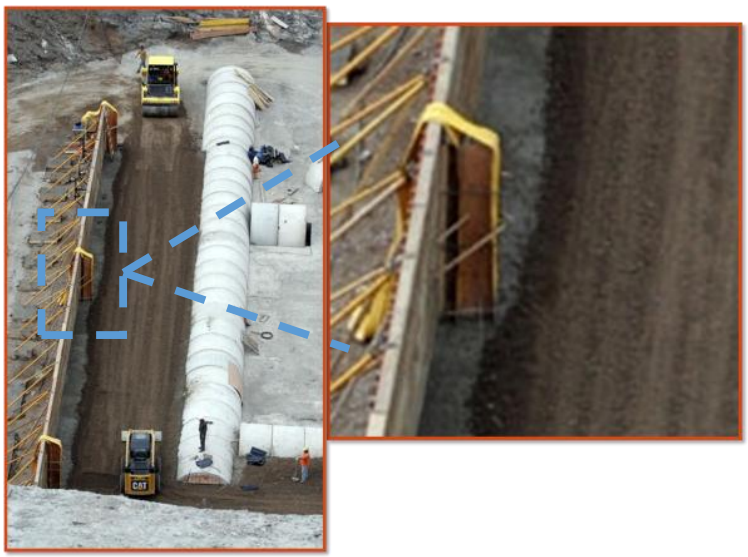

Figure 4. Photos. Shows the lack of detail in the placement of the gasket water-stop.

Defect of compaction in RCC layers. If the capacity of the equipment of compaction is not appropriate, stratification occurs in the RCC layer. The bottom of the layer is less dense or with higher porosity that the top layer. 
Proc. of Eighth International Conference On Advances in Civil, Structural and Mechanical Engineering - ACSM 2018 Copyright (C) Institute of Research Engineers and Doctors, USA. All rights reserved. ISBN: 978-1-63248-154-2 doi: 10.15224/978-1-63248-154-2-27

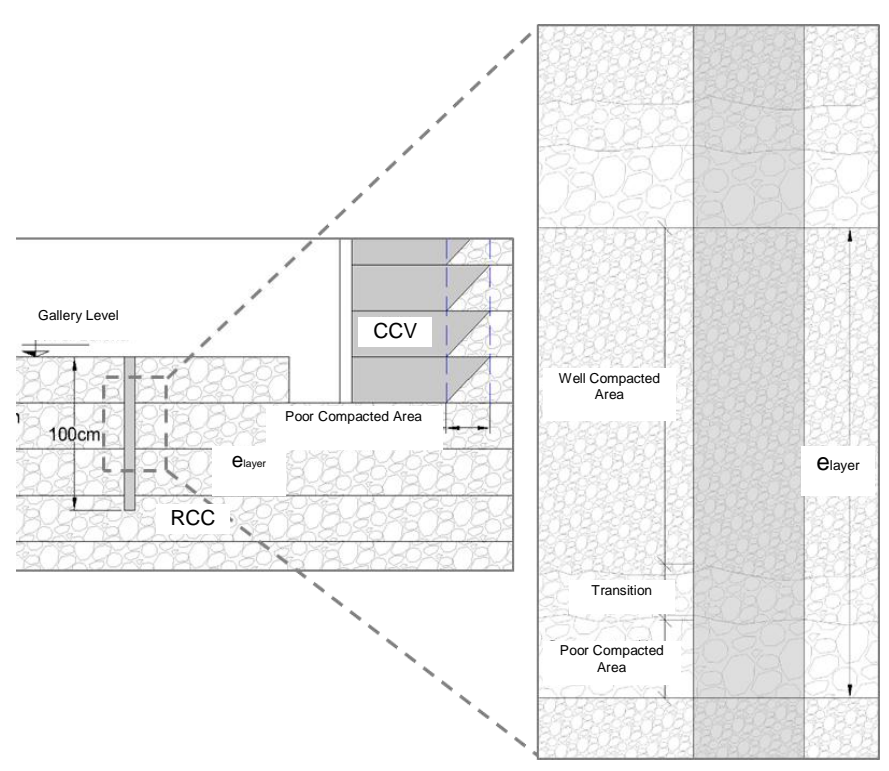

Figure 5. Photos se muestra un esquema de la estratificación en el grado de compactación del RCC.

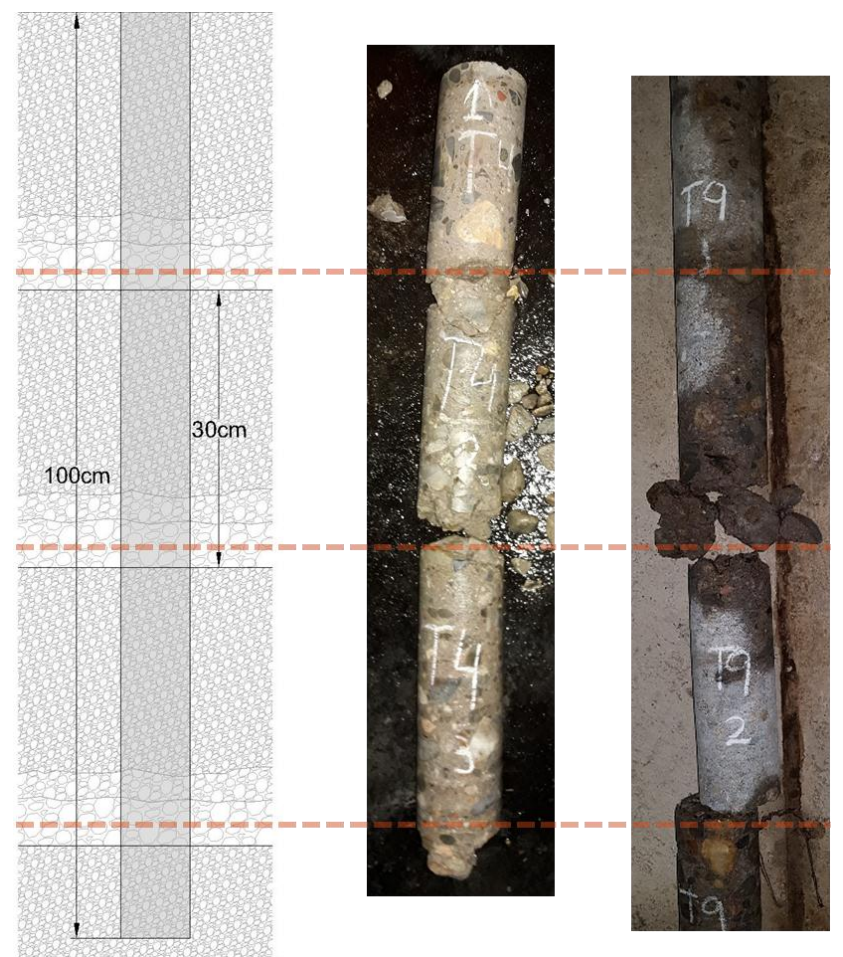

Figure 6. Photos of openwork witnesses on which you can see stratification in the degree of compaction of the RCC.

\section{Origin and trajectory of leaks}

The origin of the leaks is due to the existence of cracks in the wall and defects sealed joints water-stop. A diagram that shows how it is the origin of leaks and its trajectory through the body of the dam is presented in figures 7 and 8 .
It establishes a network of flow complex in the body of the dam water that passes the Paramento is defective compaction zones (contact RCC-CCV- Figure3) longitudinally and transversely to the same through the area of compaction defective in RCC layers and horizontal joints between layers (Figure 5).

The water from the reservoir has no aggressive elements to concrete. However, the same occurs leaching of hydroxide calcium $\left[\mathrm{Ca}(\mathrm{OH})_{2}\right]$ the $\mathrm{RCC}$, in a process of progressive deterioration, which could compromise the security of the dam.

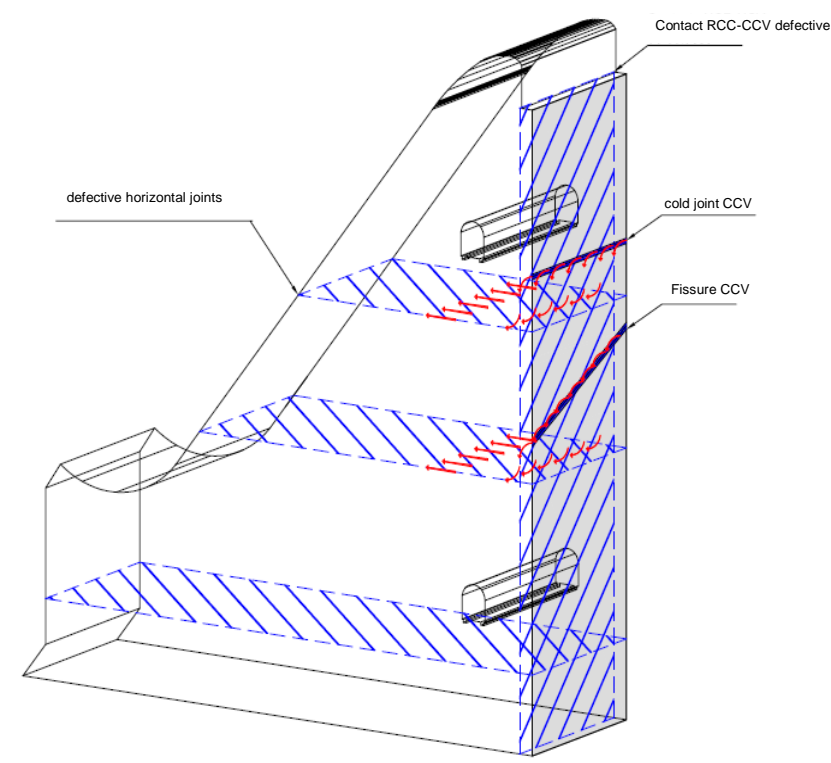

Figure 7. Se muestra un esquema del ingreso de agua y de la red de flujo través del cuerpo de la presa.

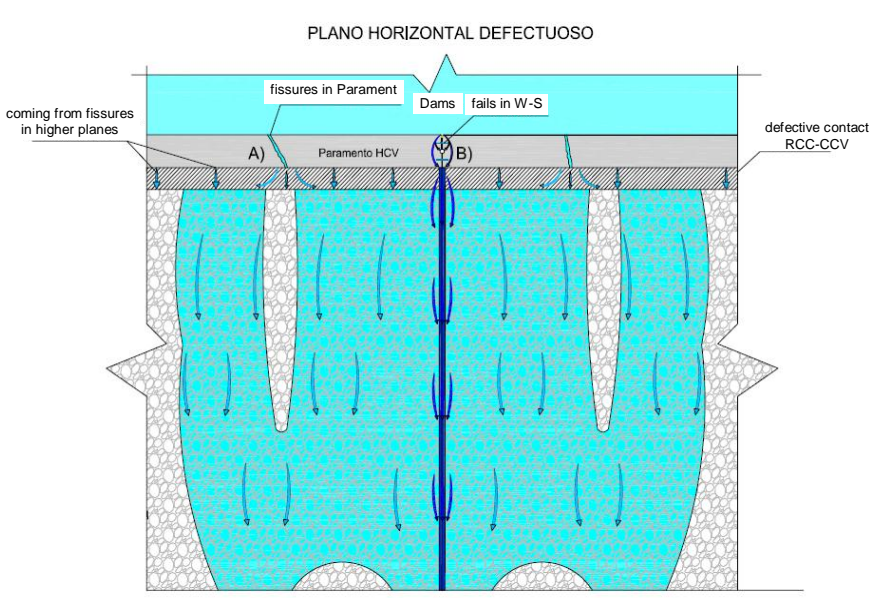

Figure 8. Shows a horizontal section showing the water circulating through the body of the dam and the vertical joints. 


\section{Conclusions}

The results obtained in the present work allow the following conclusions to be drawn:

a. Water enters through cracks in the Paramento and defects of sealing and anchoring of the Board waterstop.

b. The measured flows might be admissible, without however progressive deterioration processes may affect the safety of the dam.

c. It is strongly recommended to pay attention to the methodology of placement and compaction of the concrete, especially in the areas of contact between the RCC-CCV and the RCC with the rock of the Stirrups.

d. It is advisable to adjust, control and properly certify the proper placement, anchoring and sealing joints water-stop.

e. Defects in concrete contacts with the rock of the Stirrups, also facilitate the flow of water, can seriously compromise the safety of the dam.

f. An intervention of the dam with injections of resins of high viscosity is recommended to restore the impermeability of the Paramento.

g. Also, contacts between RCC and the stirrups of foundation should be injected with grout.

\section{References}

[1] Roller Compacted Concrete Engineer Manual M 1110-2-2006. US Army Corps of Engineers.

[2] CANNON, ROBERT W. (1995) - Seismic Design Provisions for Roller Compacted Concrete Dams; Appendix E, Tensile Strength of Roller Compacted Concrete, Engineer Pamphlet 1110-2-12, U.S. Army Corps of Engineers.

[3] Roller-Compacted Mass Concrete. ACI Committee 207.

[4] MORANDI J., ULIARTE R. Direct Tensile Strength in Joint of Roller Compacted Concrete Dams. Proc. of the Fifth International Conference on Advances in Civil, Structural and Environmental Engineering - ACSEE 2017 - Roma.

[5] STRUCTURAL DESIGN USING THE ROLLER-COMPACTED CONCRETE (RCC) CONSTRUCTION PROCESS. ETL 1110-2343-93.

[6] ROCCO, MORANDI, FAVA, GIOVAMBATTISTA (2010) Resistencia a la tracción de juntas de hormigón compactado a rodillo en presas, Congreso Internacional de Tecnología del Hormigón, Mar del Plata - Argentina.

About author (s):

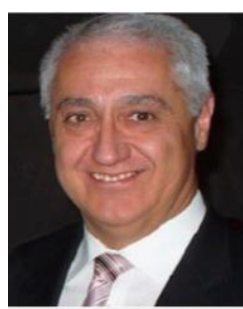

M. Cs. Ing. Civil Javier O. Morandi.

Researcher Institute of Materials and Soils

Faculty of Engineering

National University of San Juan

San Juan, Argentina 